\title{
Chondromyxoid Fibroma of the Foot: An Uncommon Presentation
}

\author{
by Anil Thomas Oommen, MS (Ortho), DNB (Ortho) ${ }^{1} 凹$, Vrisha Madhuri, MS (Ortho), \\ $\operatorname{MCh}(\text { Ortho })^{2}$, Noel Malcolm Walter, $\mathrm{MD}^{3} \square$
}

The Foot \& Ankle Journal 2 (1): 2

We report a chondromyxoid fibroma of the proximal phalanx of the left third toe in a 35 year old woman, a rare site for this tumor. The radiological appearance of a trabeculated lytic lesion with sclerotic margins and soft tissue extension raised the possibility of other entities such as intraosseous epidermoid cyst, aneurysmal bone cyst, chondroblastoma, osteoid osteoma and chondrosarcoma as well as infections like pyogenic, tuberculous and leprous dactylitis. However the typical microscopic picture of lobules of cartilage separated by fibrocellular tissue and scattered osteoclasts confirmed the diagnosis. The tumor was successfully treated by curettage and bone grafting using a dorsal and plantar 2 incision technique and has no recurrence at 4 year follow up. In this article we present our experience with this case and discuss the differential diagnosis of a solitary lytic lesion in the phalanges of the toes.

Key words: Foot, chondromyxoid fibroma, cartilaginous tumor, lytic lesion toe, curettage

Accepted: December, $2008 \quad$ Published: January, 2009

This is an Open Access article distributed under the terms of the Creative Commons Attribution License. It permits unrestricted use, distribution, and reproduction in any medium, provided the original work is properly cited. @The Foot \& Ankle Journal (www.faoj.org)

\begin{abstract}
A 35 year old housewife presented with a swelling on the dorsal aspect of the right third toe which had been present for 10 years with gradual increase in size. On examination an ovoid swelling measuring $1.5 \times 1.5 \mathrm{~cm}$ and extending from the metatarso-phalangeal joint up to the middle of the toe was noted. There was fullness on the plantar aspect of the third toe which extended to the web space on either side with the two adjacent toes being pushed aside as a result. Radiological examination revealed a trabeculated lytic lesion with sclerotic margins involving half the length of the proximal phalanx of the third toe. (Fig. 1 )
\end{abstract}

\footnotetext{
Address correspondence to: Dr Anil Thomas Oommen MS(Ortho)

Assistant Profressor, Dept. of Orthopaedics, Unit 2

Christian Medical College Ida Scudder Road,Vellore 632004.

${ }^{1}$ Assistant Profressor, Department of Orthopaedics, Unit 2 Christian Medical College Ida Scudder Road,Vellore 632004.

${ }^{2}$ Profressor, and Head, Department of Orthopaedics, Unit 2

Christian Medical College Ida Scudder Road,Vellore 632004.

${ }^{3}$ Profressor, Department of Pathology,

Christian Medical College Ida Scudder Road,Vellore 632004.
}

A needle biopsy was reported as benign cartilaginous tumor. Through a combined dorsomedial and plantar approach the soft tissue component was excised. The tumor was thoroughly curetted after making a window over the dorsomedial aspect of the proximal phalanx. The plantar approach was added to ensure complete clearance of soft tissue extension which was predominantly on the plantar aspect. The cavity was then filled with cancellous bone graft harvested from the ipsilateral proximal tibia.

Microscopic evaluation of the curetted tissue revealed a tumor composed of lobules of cartilage separated by fibrocellular tissue. (Fig. 2) Osteoclast-like cells were scattered along the interface between these tissues.(Fig. 3) There was no histological evidence of malignancy. At 4 years follow up there is no recurrence. (Figs. 4,5) 


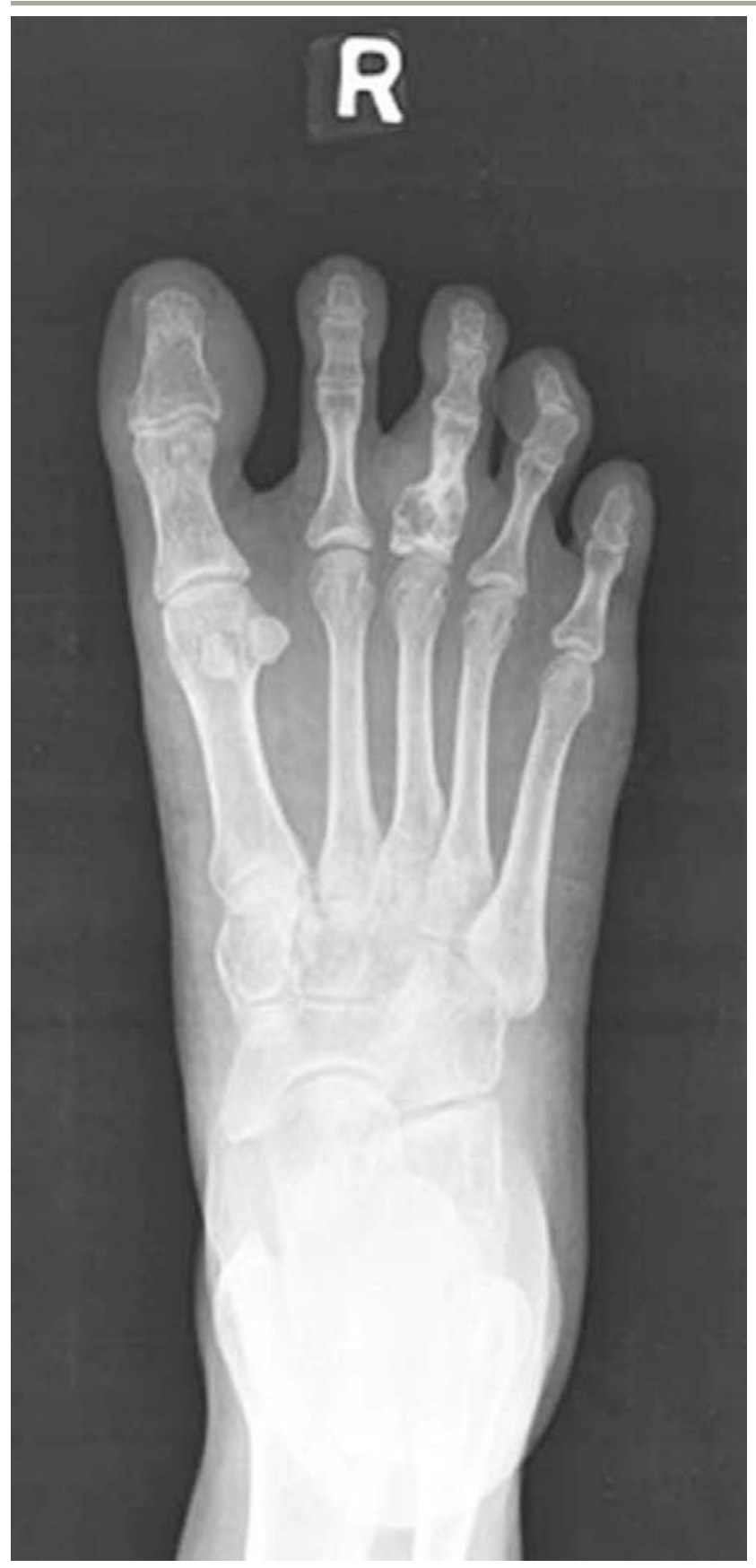

Figure 1 Eccentric expansile well defined lytic lesion showing intra lesional trabeculae and thinned medial cortex of the proximal phalanx of the third toe. Soft tissue swelling around the base of 3rd toe and widening of the webspaces is noted.

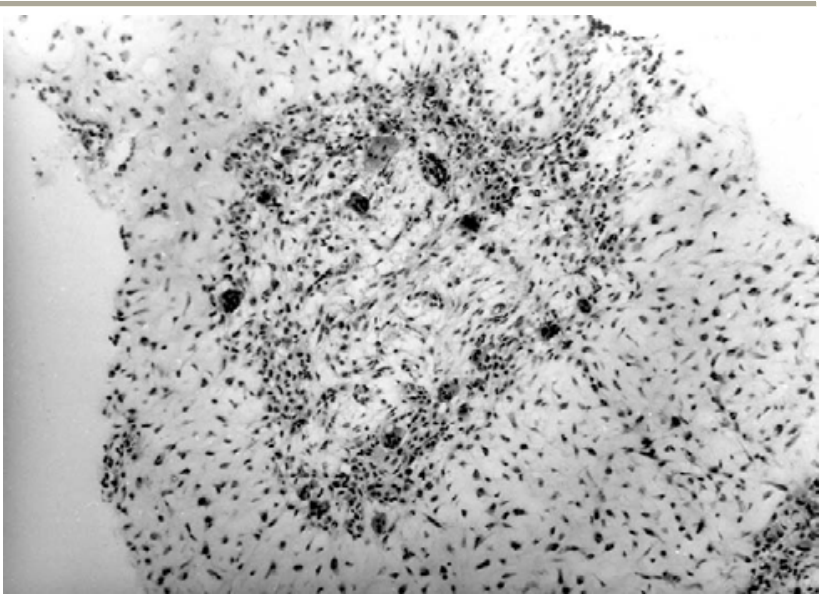

Figure 2 Lobules of cartilage separated by fibrocellular tissue. (HPE H\&E x 100)

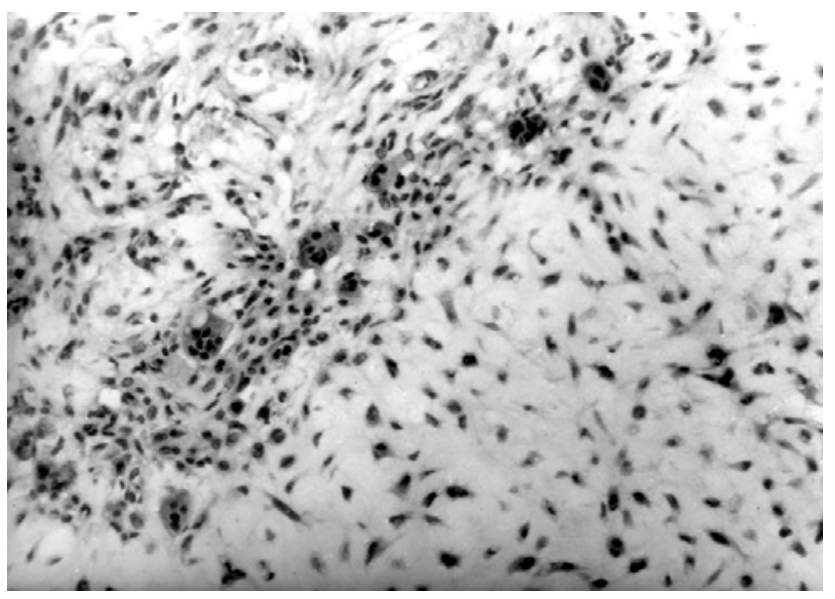

Figure 3 Osteoclast like cells along the edge of chndromyxoid areas. (HPE H\&E x 200)

\section{Discussion}

Chondromyxoid fibroma (CMF) is a rare neoplasm constituting less than $1 \%$ of all bone tumors. ${ }^{1,2}$ It is derived from skeletal connective tissue cells which demonstrate the capacity to produce chondro-myxoid matrix in a distinctive histological pattern. The peak incidence is in the second and third decades of life. The most common bones affected are those of the lower extremities and in only $5 \%$ of cases are the toes involved. $^{2}$ 


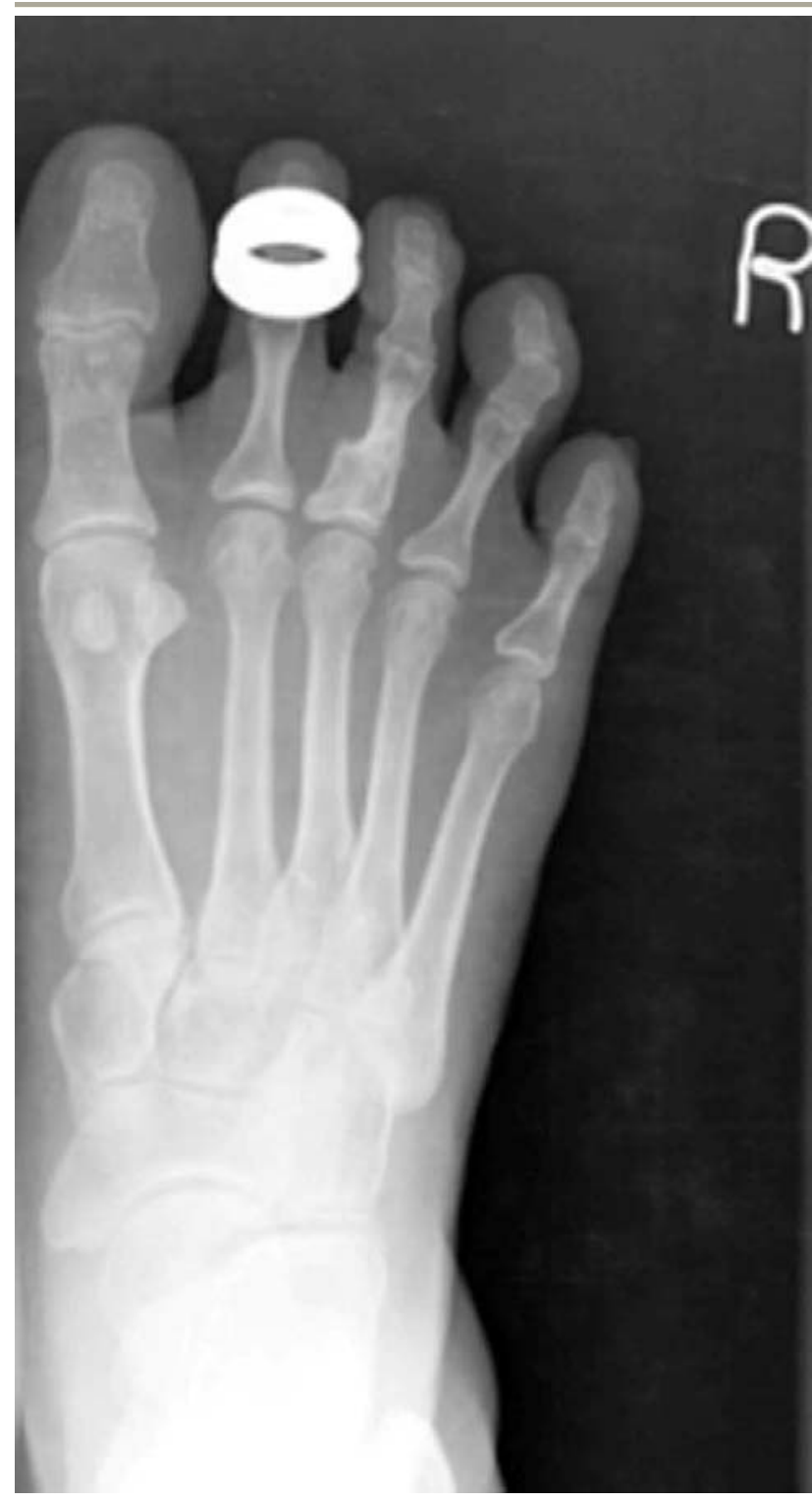

Figure 4 Radiograph 4 years post op AP shows sclerosis and healed lesion.

CMF in the long bones is usually metaphyseal and eccentrically located with well defined sclerotic margins on radiological evaluation. Lesions in the small bones are osteolytic with scalloped margins, an appearance which overlaps with NonOssifying Fibroma. Calcification within the lesion is visible in most cases. ${ }^{3,4}$ There is attenuation, expansion or erosion of the overlying cortex. It usually occurs in the metaphyseal side of the growth plate which is situated proximally in the phalanges.

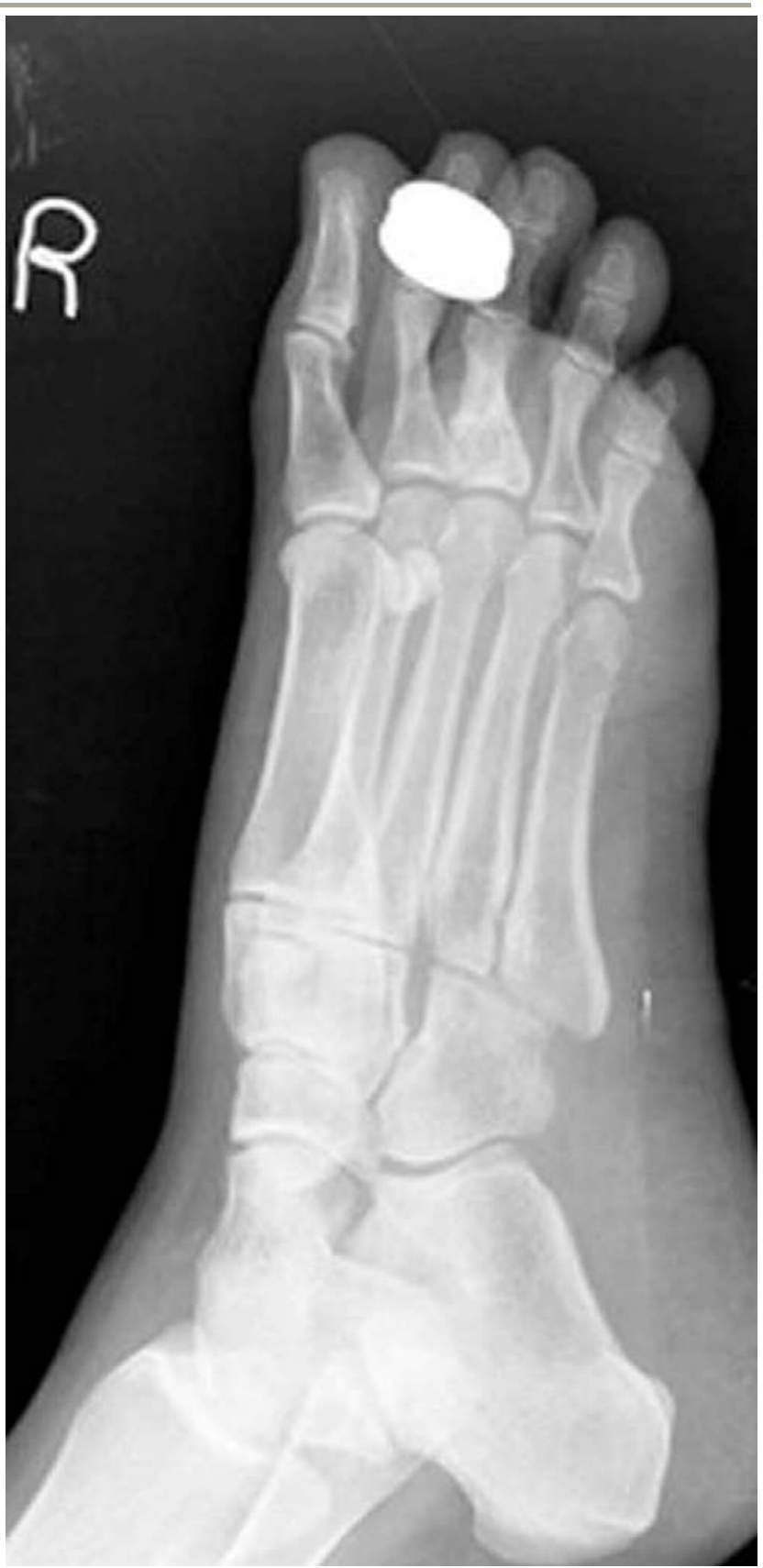

Figure 5 Oblique radiograph showing healed lesion 4 years post op.

Intra-medullary tumours and tumour-like lesions of the toe phalanges are rare. Among benign lesions enchondroma is probably the most common and may be clinically and radiologically indistinguishable from $\mathrm{CMF}^{5}$ 
The diagnosis can usually be made by biopsy because CMF is mostly myxoid and often has osteoclastic giant cells whereas enchondroma is generally more obviously cartilaginous and lacks giant cells. However a small biopsy may not have enough tissue for this distinction and in such instances the only diagnosis possible may be "benign cartilaginous tumour" as in this case. Other benign tumours or tumour-like lesions which may rarely occur in the toes include aneurysmal bone cyst, the closely related giant cell reparative granuloma, and true giant cell tumour all of which are histologically quite different from $\mathrm{CMF}^{5}$

Chondroblastoma can be partially or largely similar to CMF microscopically but is virtually unknown in the toes. ${ }^{2}$ Among malignant bone tumours chondrosarcoma can be histologically difficult to distinguish from CMF. For making this differentiation the $\mathrm{x}$-ray is critical as the radiological appearance of chondrosarcoma is aggressive, unlike that of CMF. The toes are also an extremely uncommon site for chondrosarcoma.

Other than benign cartilage lesions, a few other tumors of the terminal digits should be considered in the differential diagnosis. A radiological diagnosis of intraosseous epidermoid cyst can be made in the presence of perilesional sclerosis with painless swelling. ${ }^{5}$ A painful lesion with perifocal reactive sclerosis is suggestive of an osteoid osteoma and is easily distinguishable radiologically. ${ }^{5}$

Poorly defined lytic lesions can be associated with several pseudotumorous conditions such as osteomyelitis caused by Staphylococcus seen in diabetic patients. ${ }^{5}$ Tuberculous and leprous dactylitis are other condition which are clinically seen as phalangeal lesions. ${ }^{6} \quad$ Radiologically the tuberculous lesion is central, lytic, cystic and expansive, and soft tissue extension may be seen. ${ }^{5}$ These are easily distinguished histologically.
As our report shows, a needle biopsy is of great value in suggesting the diagnosis and can easily be carried out as an outpatient procedure. Conservative surgical treatment, such as curettage and bone grafting, appears to be ideal for CMF.

In conclusion, a wide range of entities, including CMF, needs to be considered when confronted with a lytic lesion in the toe phalanx. Radiological features may help in distinguishing these conditions. Histopathology and microbiology provide a definitive diagnosis. A thorough surgical clearance is required to avoid recurrence in CMF.

\section{References}

1. Fletcher CDM, Unni KK, Mertens F (eds). Pathology and Genetics of Tumours of Soft Tissue and Bone, WHO Classification of Tumours, IARC Press, Lyon: 243 - 245, 2002.

2. Wu CT, Inwards CY, O'Laughlin S, Rock MG, Beabout JW, Unni KK. Chondromyxoid fibroma of bone: a clinicopathologic review of 278 cases. Hum Pathol 29 (5): 438 - 446, 1998.

3. Schajowicz F, Gallardo H .Chondromyxoid fibroma (fibromyxoid chondroma) of bone. A clinico-pathological study of thirty-two cases.J Bone Joint Surg. 53B (2): 198216,1971 .

4. Sharma H.,Jane M J, Reid R. Chondromyxoid fibroma of the foot and ankle: 40 years' Scottish bone tumour registry experience. Int Orthop. 30(3): 205 - 209, 2006.

5. Wang BY, Eisler J, Springfield D, Klein MJ. Intraosseous Epidermoid Inclusion Cyst in a Great Toe. A Case Report and Review of the Literature. Arch Pathol Lab Med. 27 (7): 298 - 300, 2003.

6. Olivieri .I.,Scarano E,Padula A,Giasi V,Priolo F. Dactylitis,a term for different digit diseases. Scand J Rheumatol. 35(5): 333 - 340, 2006. 